\title{
The relative dispersion of cloud droplets: its robustness with respect to key cloud properties
}

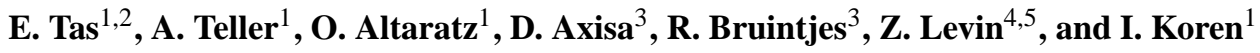 \\ ${ }^{1}$ Department of Earth and Planetary Sciences, Weizmann Institute of Science, Rehovot, Israel \\ ${ }^{2}$ Department of Soil and Water Sciences, The Robert H. Smith Faculty of Agriculture, \\ Food and Environment, The Hebrew University of Jerusalem, Rehovot, Israel \\ ${ }^{3}$ Research Applications Laboratory, National Center for Atmospheric Research, Boulder, CO, USA \\ ${ }^{4}$ Department of Geophysics and Planetary Science, Tel Aviv University, Israel \\ ${ }^{5}$ The Energy, Environment and Water Research Center, the Cyprus Institute, Nicosia, Cyprus \\ Correspondence to: I. Koren (ilan.koren@weizmann.ac.il)
}

Received: 25 March 2014 - Published in Atmos. Chem. Phys. Discuss.: 6 May 2014

Revised: 28 December 2014 - Accepted: 23 January 2015 - Published: 24 February 2015

\begin{abstract}
Flight data measured in warm convective clouds near Istanbul in June 2008 were used to investigate the relative dispersion of cloud droplet size distribution. The relative dispersion $(\varepsilon)$, defined as the ratio between the standard deviation $(\sigma)$ of the cloud droplet size distribution and cloud droplet average radius $(\langle r\rangle)$, is a key factor in regional and global models. The relationship between $\varepsilon$ and the clouds' microphysical and thermodynamic characteristics is examined. The results show that $\varepsilon$ is constrained with average values in the range of $\sim 0.25-0.35$. $\varepsilon$ is shown not to be correlated with cloud droplet concentration or liquid water content (LWC). However, $\varepsilon$ variance is shown to be sensitive to droplet concentration and LWC, suggesting smaller variability of $\varepsilon$ in the clouds' most adiabatic regions. A criterion for use of in situ airborne measurement data for calculations of statistical moments (used in bulk microphysical schemes), based on the evaluation of $\varepsilon$, is suggested.
\end{abstract}

\section{Introduction}

Droplet size distribution is one of the most important variables in the study of cloud physics. The size distribution properties are controlled by the thermodynamic conditions and by the microphysical and dynamic state of the cloud. Near the cloud base at the first stage of droplet formation, the size distribution is determined by the supersaturation (determined by the thermodynamic conditions and the updraft) and the aerosol properties. Higher in the cloud, at later stages of the cloud's development, additional processes (such as collision-coalescence, raindrop sedimentation, entrainment, and mixing) further modify the drops' size distribution. On the other hand, the droplet size distribution determines the timing and magnitude of microphysical processes, which affect the cloud's dynamics through determination of terminal velocities, drag of the falling raindrops, and the release of latent heat.

The relative dispersion of cloud droplets $(\varepsilon)$ is a parameter that represents droplet size distribution. It is defined as the ratio between the standard deviation $(\sigma)$ and the mean radius $(\langle r\rangle)$ of the clouds' droplet distribution. Both $\sigma$ and $\langle r\rangle$ are key variables used in various parameterization schemes, such as reflectivity of clouds (Hansen and Travis, 1974; Slingo, 1989; Liu and Daum, 2000a, b; Daum and Liu, 2003) and autoconversion processes (e.g., Liu et al., 2005, 2006a; Hsieh et al., 2009). However, instead of using both $\sigma$ and $\langle r\rangle$, their ratio (i.e., the relative dispersion, $\varepsilon$ ) is often used. This is done in atmospheric models that span a wide scale from cloud resolving models (CRMs) to global climate models (GCMs). These models are used to explore aerosol effects on clouds, such as the first and second indirect aerosol effects: the first effect links higher aerosol loading to the formation of numerous but smaller cloud droplets and higher cloud reflectivity (Twomey, 1977), and the second effect links the increase in aerosol loading with an increase in cloud lifetime (Albrecht, 1989). Another effect that can be potentially explored using 
the relative dispersion is the convective cloud invigoration effect (Koren et al., 2005; Andreae et al., 2004; Tao et al., 2012; Altaratz et al., 2014).

Considering the importance of $\varepsilon$, many studies have been conducted to analyze the sensitivity of this parameter to environmental conditions and to key microphysical and thermodynamic cloud properties. This has been done in stratiform clouds (Peng and Lohmann, 2003; Rotstayn and Liu, 2003; Peng et al., 2007; Miles et al., 2000; Martin et al., 1994; Ma et al., 2010; Lu and Seinfeld, 2006; Pawlowska et al., 2006). Fewer studies have examined this parameter for convective clouds, and the reported results are quite diverse. For example, Lu et al. (2008) and Berg et al. (2011) analyzed airborne measurements of shallow cumuli under various levels of anthropogenic pollution and found an average $\varepsilon$ of around 0.3 . In Berg et al. (2012), the pollution levels were assessed using $\mathrm{CO}$ concentrations (up to $170 \mathrm{ppbv}$ ) and in $\mathrm{Lu}$ et al. (2008), the highest accumulation mode aerosol concentration was $1650 \mathrm{~cm}^{-3}$. Zhao et al. (2006) analyzed data collected in 135 flights in different environments and found that $\varepsilon$ values tend to converge to a range of $\sim 0.4$ to 0.5 for droplet concentrations $\left(N_{\mathrm{c}}\right)$ higher than $50 \mathrm{~cm}^{-3}$. Deng et al. (2009) also indicated similar convergence of $\varepsilon$ with $N_{\mathrm{c}}$. Martins and Silva Dias (2009) studied cumulus clouds in the Amazonian dry season and found $\varepsilon$ values in the range of 0.38 to 0.59 .

Some studies have examined the sensitivity of $\varepsilon$ to aerosol loading. By compiling measured data from different field studies, including warm cumulus clouds, Liu and Daum (2002) suggested that $\varepsilon$ is sensitive to and positively correlated with aerosol loading at the cloud base. This conclusion was subsequently supported by modeling (Yum and Hudson, 2005), observational data (McFarquhar and Heymsfield 2001) and theoretical studies (Liu et al., 2006b). Other investigations using observational data (Martins and Silva Dias, 2009; Hsieh et al., 2009) have suggested a negative relationship between $\varepsilon$ and aerosol loading.

$\varepsilon$ is influenced by other factors as well. Yum and Hudson (2005) and Liu et al. (2006b) studied the combined effect of updraft values and aerosol loading (as they both determine supersaturation values) on $\varepsilon$ using adiabatic condensational growth theory. These two factors are mainly influential at early stages of cloud development, before the processes of collection, sedimentation, entrainment, and mixing become dominant. They found opposite effects: an increase in $\varepsilon$ with the increase in aerosol loading and a decrease in $\varepsilon$ with the increase in updraft velocity. They suggested that continental clouds have smaller $\langle r\rangle$ and therefore, larger $\varepsilon$.

The chemical composition of aerosols is another influential factor that should be taken into account when studying $\varepsilon$. It determines the activation process and growth by condensation and therefore affects the spectral distribution of the drops and the behavior of $\varepsilon$ (Martins and Silva Dias, 2009).

Zhao et al. (2006) and Liu et al. (2008) indicated that the so-called dispersion effect (higher $\varepsilon$ in a high aerosol loading environment) may account, at least in part, for the dis- crepancies between different estimations of the first indirect effect in different studies (Feingold et al., 2003; Rosenfeld and Feingold, 2003). This effect is linked to the impact of $\varepsilon$ on the calculated effective radius. According to the dispersion effect (Liu and Daum, 2002) $\varepsilon$ is positively correlated with the aerosol loading, resulting in a larger effective radius and lower cloud reflectivity (Slingo, 1989), which can reduce the first indirect effect (e.g., Feingold et al., 2003; Rosenfeld and Feingold, 2003). Therefore the impact of aerosol loading on $\varepsilon$ should be well understood for enabling suitable use of climate models in quantifying the impact of aerosol loading on the droplet size distribution, effective radius, and clouds' reflectivity.

Xie et al. (2013) studied four types of parameterizations for treating the relationship between $N_{\mathrm{c}}$ and $\varepsilon$. They implemented these schemes into the Weather Research and Forecasting (WRF) model, aimed at studying the effects of aerosol on cloud microphysics and ground precipitation. They concluded that the $N_{\mathrm{c}}-\varepsilon$ relationship (positive or negative change of $\varepsilon$ with $N_{\mathrm{c}}$ ) influences the autoconversion process (i.e conversion of cloud droplets to raindrops), and therefore affects the response of ground precipitation to a change in aerosols concentration. Xie et al. (2013) suggested that for a positive $N_{\mathrm{c}}-\varepsilon$ relationship, the large-sized rain drops at high aerosol concentrations enhance the efficiency of the surface precipitation. The diversity of schemes for the $N_{\mathrm{c}}-\varepsilon$ relationship (as shown in Fig. 1 of Xie et al., 2013) suggests that much more research is needed to understand the physics behind the properties of $\varepsilon$.

Recently, Tas et al. (2012) monitored the response of $\varepsilon$ in warm cumulus clouds to changes in thermodynamic conditions and aerosol loading, per cloud evolutionary stage. In that work, the cloud lifetime was divided into three stages based on the dominant microphysical processes. Using a detailed microphysical model, a different pattern of $\varepsilon$ was shown for each stage. Their results indicated that $\varepsilon$ has a narrow range around $\sim 0.25-0.35$ during the mature stage of the cloud's lifetime (defined as the stage when the total water mass is around its maximum with only minor changes). They claimed that trends in $\varepsilon$ can be explained by the balance between the two main growth processes that dictate the droplet size distribution, condensation and collisioncoalescence (before the initiation of significant rain). At the mature stage, the relative importance of the collisioncoalescence-induced growth slowly increases, such that $\varepsilon$ growth is relatively slow.

In this study, we use detailed airborne measurements carried out near Istanbul, Turkey in June 2008, to explore $\varepsilon$ in non-precipitating continental convective clouds under various conditions of aerosol loading. 


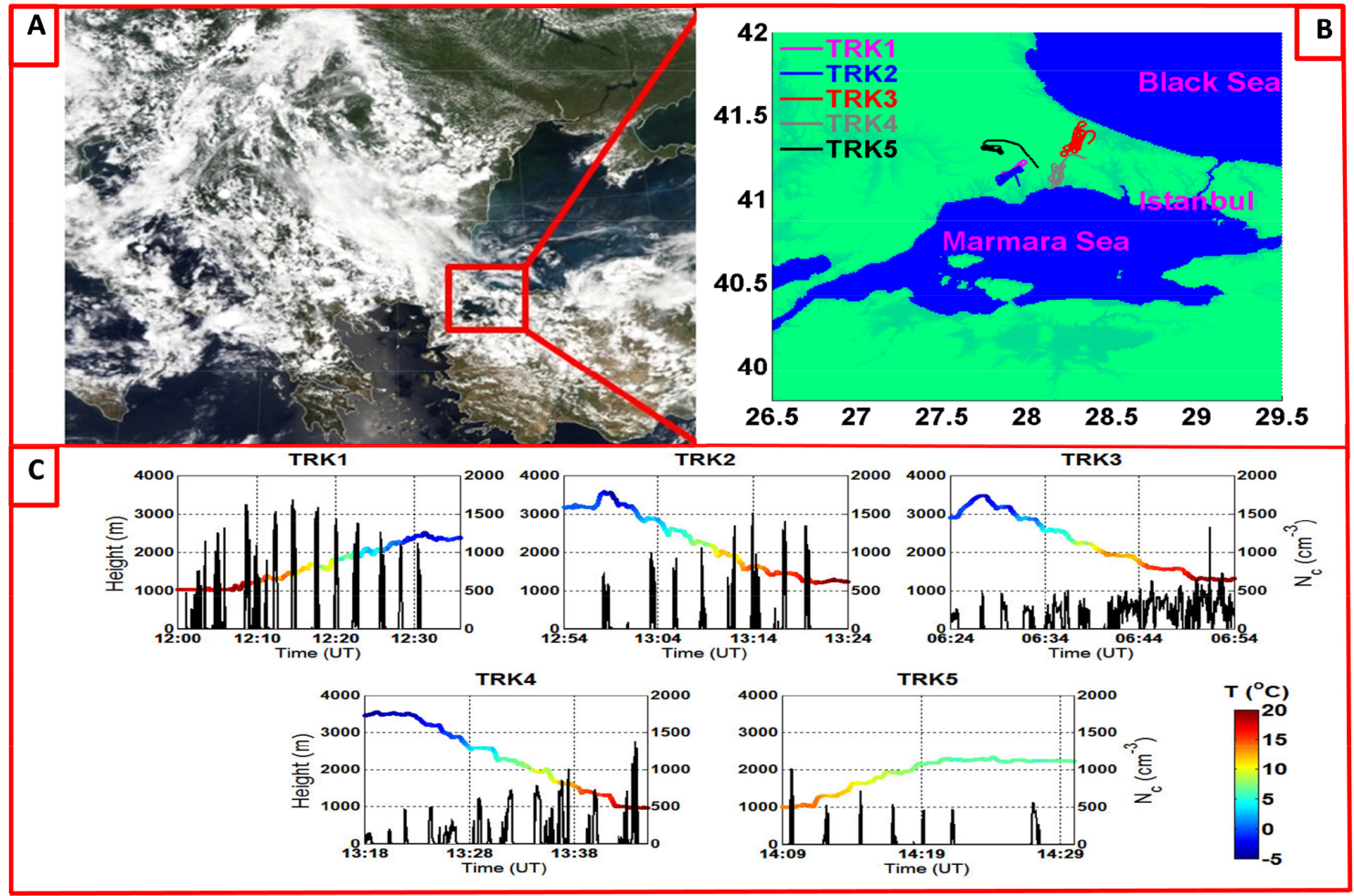

Figure 1. (a) MODIS image of the eastern Mediterranean region on 7 June 2008. (b) The tracks of the five flights. (c) A summary of flight profiles and cloud droplet concentration in airborne measurements carried out on 6-7 June 2008 around Istanbul, Turkey. Black line shows the droplet concentration and colored line shows the height above ground and the temperature.

\section{Measurements and instrumentation}

The 2007-2008 Cloud and Aerosol Research in Istanbul (CARI) project was aimed at exploring cloud and precipitation characteristics as a feasibility study for cloud-seeding operations in the area of Istanbul (Teller et al., 2008). A Piper Cheyenne II research aircraft (see Axisa et al., 2005 for details of the aircraft) was equipped with a Droplet Measurement Technologies (DMT) cloud droplet probe (CDP) to measure the concentration and size distribution of cloud droplets in the radius range of $1.5-25 \mu \mathrm{m}$. In addition, aerosol concentrations and size distributions in the radius range of $0.055-1.5 \mu \mathrm{m}$ were measured using a DMT passive cavity aerosol spectrometer probe (PCASP, SPP200). This work focuses on the measurements that were carried out on 6-7 June 2008.

Each flight focused on one single cloud with penetrations at different altitudes (the aircraft ascended or descended at height steps of approximately $150 \mathrm{~m}$ ). As can be inferred from Fig. 1c, the duration of each penetration was about 15$25 \mathrm{~s}$, corresponding to horizontal flight distances of approximately $1-2 \mathrm{~km}$ (the aircraft speed was $70-90 \mathrm{~m} \mathrm{~s}^{-1}$ depending on the wind speed and direction). The information about cloud top height presented in this paper is based on verification that no cloudy region was present above a specific height. This was done by visual inspection of the visibility around the aircraft, combined with the measured cloud droplet concentration and LWC above this height. Cloud top height was set as the highest altitude for which measured cloud droplet concentration and LWC were higher than $10 \mathrm{~cm}^{-3}$ and $0.01 \mathrm{~g} \mathrm{~kg}^{-1}$, respectively, in agreement with the criteria of Deng et al. (2009) for the determination of a cloudy region.

A shallow frontal system passed over the area of Istanbul on the night of 6 June 2008, bringing some rain showers to the area. Figure 1a shows an image of the eastern Mediterranean region, taken by the Moderate Resolution Imaging Spectroradiometer (MODIS) sensor, on 7 June 2008, showing the area west of Istanbul after passage of the front. The airborne measurements in five warm cumulus clouds were conducted before (clouds TRK1 and TRK2) and after (TRK3, TRK4 and TRK5) the passage of the front (see the flight tracks in Fig. 1b). There was a slight decrease in temperature after the passage of the front (this can be seen in the minor differences between the temperature levels of TRK1 and TRK 2 compared to those of TRK3, TRK4, and TRK5 in Table 1). Such measurements provide a unique opportunity to study the relationships between relative dispersion $(\varepsilon)$ and different cloud properties (e.g., height above the cloud base, LWC, $N_{\mathrm{c}}$ ). 
Table 1. Airborne measurements used for the present study. For each of the five airborne measurements used in the present study, the flight date and the corresponding abbreviation used in this paper, number of data points, aerosol loading at the cloud base (see Sect. 2) minimum and maximum temperature, minimum and maximum pressure, cloud base and (estimated) cloud top height are indicated.

\begin{tabular}{lcccccc}
\hline $\begin{array}{l}\text { Flight date/ } \\
\text { time (LT) }\end{array}$ & Abbr. & $\begin{array}{c}\text { No. of data } \\
\text { points(rounded) }\end{array}$ & $\begin{array}{c}\text { Aerosol loading } \\
\left(\mathrm{cm}^{-3}\right)(0.11-3 \mu \mathrm{m})\end{array}$ & $\begin{array}{c}\text { Min.-max. } \\
\text { temp. }\left({ }^{\circ} \mathrm{C}\right)\end{array}$ & $\begin{array}{c}\text { Min.-max. } \\
\text { height AGL }(\mathrm{m})\end{array}$ & $\begin{array}{c}\text { Min.-max. } \\
\text { pressure }(\mathrm{mb})\end{array}$ \\
\hline $\begin{array}{l}\text { 6 June 2008/ } \\
\text { 12:00-12:36 }\end{array}$ & TRK1 & 380 & 1800 & $5.7-16$ & $1000-2500$ & $750-901$ \\
6 June 2008/ & TRK2 & 240 & 900 & $-2.1-15.4$ & $1200-3550$ & $655-882$ \\
12:54-13:24 & & & & & & \\
7 June 2008/ & TRK3 & 1040 & 700 & $-1.3-9.8$ & $1250-3450$ & $661-874$ \\
06:24-06:54 & & & & & & \\
7 June 2008/ & TRK4 & 450 & 800 & $-1.4-13.6$ & $950-3550$ & $660-907$ \\
13:18-13:45 & & & & & & \\
7 June 2008/ & TRK5 & 110 & 1000 & $5.7-13.9$ & $1000-2350$ & $767-905$ \\
14:09-14:30 & & & & & & \\
\hline
\end{tabular}

Table 1 presents some details about each measured cloud: the time of the measurement, the top and base height levels and the corresponding temperature and pressure levels, and aerosol loading. Further details are provided below.

Flights of 6 June 2008: on this day, the research aircraft conducted two flights to measure two cumulus clouds that developed west of the urban area of Istanbul. These clouds are referred to as TRK1 and TRK2 (see Fig. 1). The thickness of the two clouds was around $2000 \mathrm{~m}$, with a cloud base temperature of about $15^{\circ} \mathrm{C}$ and cloud top temperature between 0 and $-2{ }^{\circ} \mathrm{C}$. Cloud imaging probe (CIP) measurements, carried out onboard the aircraft, showed that the clouds did not contain ice hydrometeors.

Flights of 7 June 2008: three flights were conducted on this day in three cumulus clouds west of Istanbul - TRK3, TRK4 and TRK5 (see Fig. 1). The environmental conditions of clouds TRK3 and TRK4 and their physical sizes were quite similar to TRK1 and TRK2. TRK5 was a shallower cloud of only $1000 \mathrm{~m}$ depth and a cloud top temperature of $8^{\circ} \mathrm{C}$.

To ensure statistically significant results, we analyzed only cloud measurements with droplet concentrations larger than $10 \mathrm{~cm}^{-3}$ and LWC $>0.01 \mathrm{~g} \mathrm{~kg}^{-1}$ as in Deng et al. (2009). Sensitivity tests revealed that the results do not change significantly by applying other threshold values to define the clouds' boundaries, within a droplet concentration range of $5-50 \mathrm{~cm}^{-3}$, or LWC range of $0.001-0.1 \mathrm{~g} \mathrm{~kg}^{-1}$. Analyses were performed for two types of cloud regions: (i) inner cloud and (ii) cloud boundary.

The more adiabatic, inner cloud data set required that not only the sampling point itself, but also two neighboring sampling points (representing in total $2 \mathrm{~s}$ or $\sim 140 \mathrm{~m}$ ) all be associated with measured concentrations higher than $10 \mathrm{~cm}^{-3}$ and LWC higher than $0.01 \mathrm{~g} \mathrm{~kg}^{-1}$. The cloud boundaries were defined as those data intervals that met the condition of concentration $>10 \mathrm{~cm}^{-3}$ and LWC $>0.01 \mathrm{~g} \mathrm{~kg}^{-1}$, but one of their neighboring points did not meet this criterion.

\section{Results}

Figure 1c shows some differences between the clouds that were investigated on 6 and 7 June. The measurements of TRK1 and TRK2 (6 June 2008) show an increase and then a decrease in the maximum total cloud droplet concentration as a function of altitude (each penetration was $15-25 \mathrm{~s}$, corresponding to a flight distance of $1-2 \mathrm{~km}$ ). A maximum of $1650(1400) \mathrm{cm}^{-3}$ was measured at the cloud base and 1100 (700) $\mathrm{cm}^{-3}$ at the cloud top in cloud TRK1 (TRK2). The ambient aerosol concentration in the diameter range of 0.11$3 \mu \mathrm{m}$ below the cloud base was about $1800 \mathrm{~cm}^{-3}$ in the case of cloud TRK1 and $900 \mathrm{~cm}^{-3}$ for cloud TRK2.

The cloud droplet concentrations measured on 7 June 2008 were smaller than those measured on 6 June, and most of the penetrations were smaller than $1000 \mathrm{~cm}^{-3}$ (see Figs. 1 and 2). The average aerosol concentration for the morning flight (TRK3) was $700 \mathrm{~cm}^{-3}$, whereas for the afternoon flights (TRK4 and TRK5) it increased to $1000 \mathrm{~cm}^{-3}$.

Figure 2 shows the average droplet size distribution per height level. The height above ground level is binned into 10 intervals. The mean droplet radius $(\langle r\rangle)$ and the standard deviation $(\sigma)$ at each height interval is shown by the yellow and red lines, respectively. Note that due to instrumental limitations of the CDP, the maximal measured drop size was equal to a radius of $\sim 25 \mu \mathrm{m}$.

Such representation of the size distribution (see Fig. 2) allowed us to investigate the impact of the instrumental limitation on our analysis. It revealed that in all cases except TRK3, the upper limit cut-off droplet size was below $25 \mu \mathrm{m}$, implying that no larger droplets were present. TRK3, having a lower aerosol loading (see Table 1), had a lower cloud droplet concentration (see Fig. 3b) and a broader size distribution (Fig. 2). Thus, although a contribution from larger droplets was expected, it could not be included in the analysis. This limitation suggests that calculations of moments of the size distribution might be biased in the case of TRK3. 


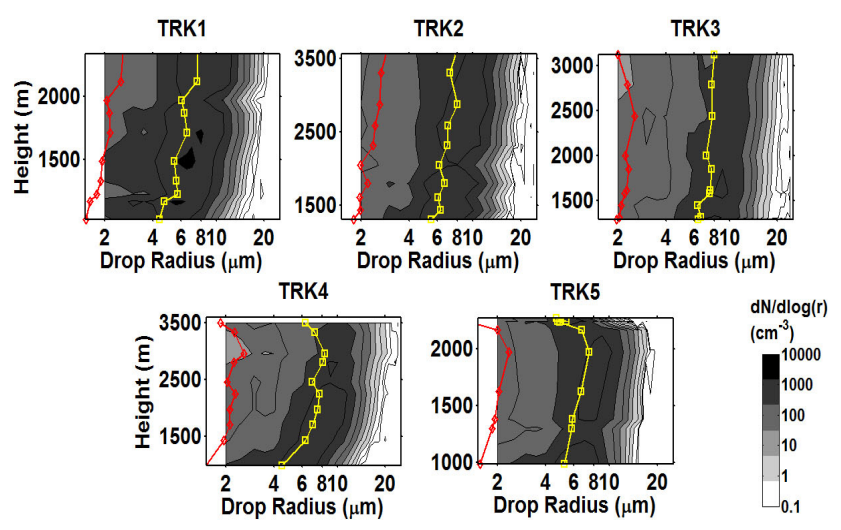

Figure 2. Cloud droplet size distribution as a function of height above the ground. The contours show the distribution $(\mathrm{d} N / \mathrm{d} \log (D))$. The yellow and red lines represent the average and standard deviation of the radius over the entire measurements, respectively. For the purpose of constructing the lines of the average radius and the standard deviation, we divided the measurements into 10 height bins, and for each bin the average was calculated. Note that the vertical axes are not uniform, accounting for the different cloud tops observed in the different flights.

Figure 2 reveals additional information about the sampled clouds: (i) cases TRK1 and TRK2 had larger droplet concentrations compared to the other clouds. In these cases, $\langle r\rangle$ was $\sim 5-6 \mu \mathrm{m}$ at the cloud base and 8-9 $\mu \mathrm{m}$ near the cloud top. As case TRK3 had the lowest droplet concentration, the average radius at the cloud base was $6.5 \mu \mathrm{m}$ and increased to about $8.5 \mu \mathrm{m}$ close to the cloud top; (ii) in cases TRK4 and TRK5, the width of the droplet size distributions decreased with altitude. In general, near the cloud tops there was a decrease in droplet concentration; (iii) TRK5 had the lowest LWC value (below $1.5 \mathrm{~g} \mathrm{~kg}^{-1}$ ).

As can be seen in Fig. 2, the changes in $\sigma$ and $\langle r\rangle$ as a function of height above the cloud base (see the red and yellow lines in the figure) were similar for all clouds except cloud TRK3. This observation suggests that, except for TRK3, the relative dispersion value $(\varepsilon=\sigma /\langle r\rangle)$ is not sensitive to the vertical height above the cloud base. The reason for the exception in case TRK3 is discussed in Sect. 4.

Figure 3 shows the relationship of the relative dispersion with height (Fig. 3a) and LWC (Fig. 3b). In Fig. 3a, the colors of the points for the average $\varepsilon$ represent the average LWC, and it can be seen that the average relative dispersion changes very little as a function of height. In Fig. 3b, the colors of the points for the average $\varepsilon$ represent the droplet concentrations. The black lines in both figure panels represent the average values of $\varepsilon$, obtained for each of the 10 different bins, and sorted in the figure according to height (Fig. 3a) or LWC (Fig. 3b). The error bars represent the $95 \%$ confidence interval for the mean $\varepsilon$. While it is clear that on average for each flight, the droplet concentration increases with LWC (see colors of the average $\varepsilon$ points), the average relative

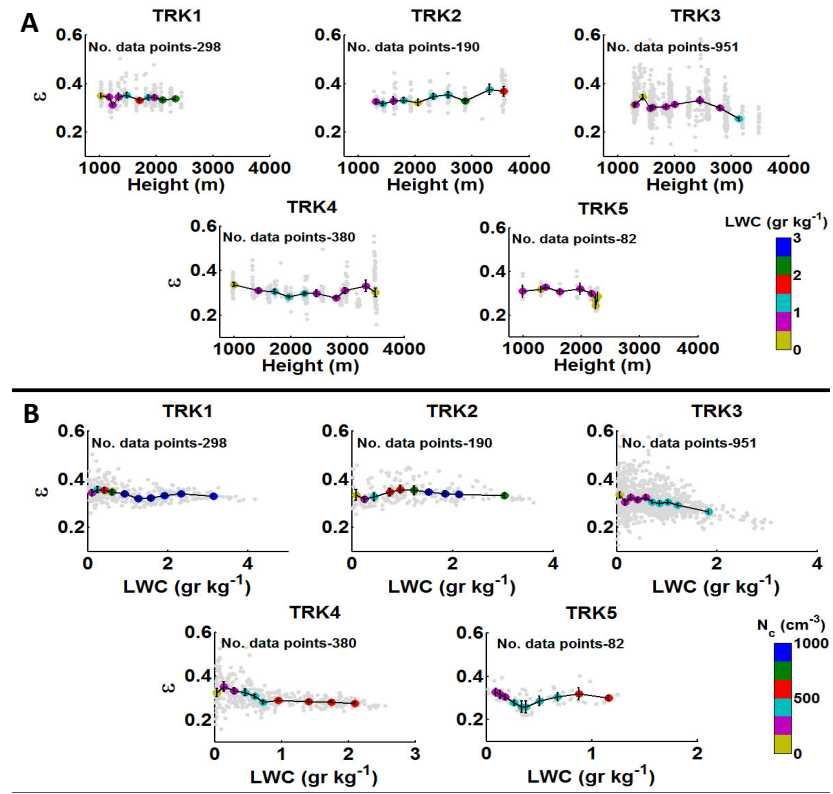

Figure 3. (a) Relative dispersion $(\varepsilon)$ vs. height above the ground with colors representing the liquid water content (LWC) and (b) $\varepsilon$ vs. LWC with colors representing the droplet concentration for the inner cloud data points. Error bars represent standard error of the average $\varepsilon$ for each height level (in a) and LWC (in b) with a confidence level of $95 \%$.

dispersion falls into a narrow range and does not depend on LWC. Figure 4 is similar to Fig. 3, but is based only on measurements in the cloud boundaries where LWC and $N_{\mathrm{c}}$ are below the threshold values of $0.01 \mathrm{~g} \mathrm{~kg}^{-1}$ and $10 \mathrm{~cm}^{-3}$, respectively. Figures 3 and 4 demonstrate that for both the inner cloud and its boundaries, the droplet concentration increases with LWC, while the average relative dispersion remains almost constant. Moreover, apart from differences in the total number of data points, the results near the cloud boundary (entrainment zones) are similar to those near the inner parts (the more adiabatic regions of the cloud). The similar relative dispersion values when comparing Figs. 3 and 4 and the decrease in LWC and $N_{\mathrm{c}}$ suggest that a fraction of the droplets were totally evaporated due to mixing with the outside environmental air, but the shape of the droplet size distribution did not change. This implies that non-homogeneous entrainment mixing was the dominant process at the cloud boundaries, similar to the findings of Small et al. (2013).

It should be noted that although the error bars in Fig. 4 are significantly larger than in Fig. 3, both figures demonstrate invariant values of $\varepsilon$ as a function of vertical height above the cloud base and LWC. It can also be noted that the trend for the TRK3 case is different. A clear decrease in $\varepsilon$ is observed near the top of the cloud associated with higher LWC values. This issue will be further discussed in Sect. 4 .

Figure 5 presents $\varepsilon$ as a function of $\langle r\rangle$. The $\langle r\rangle$ values are binned such that each point represents different heights 

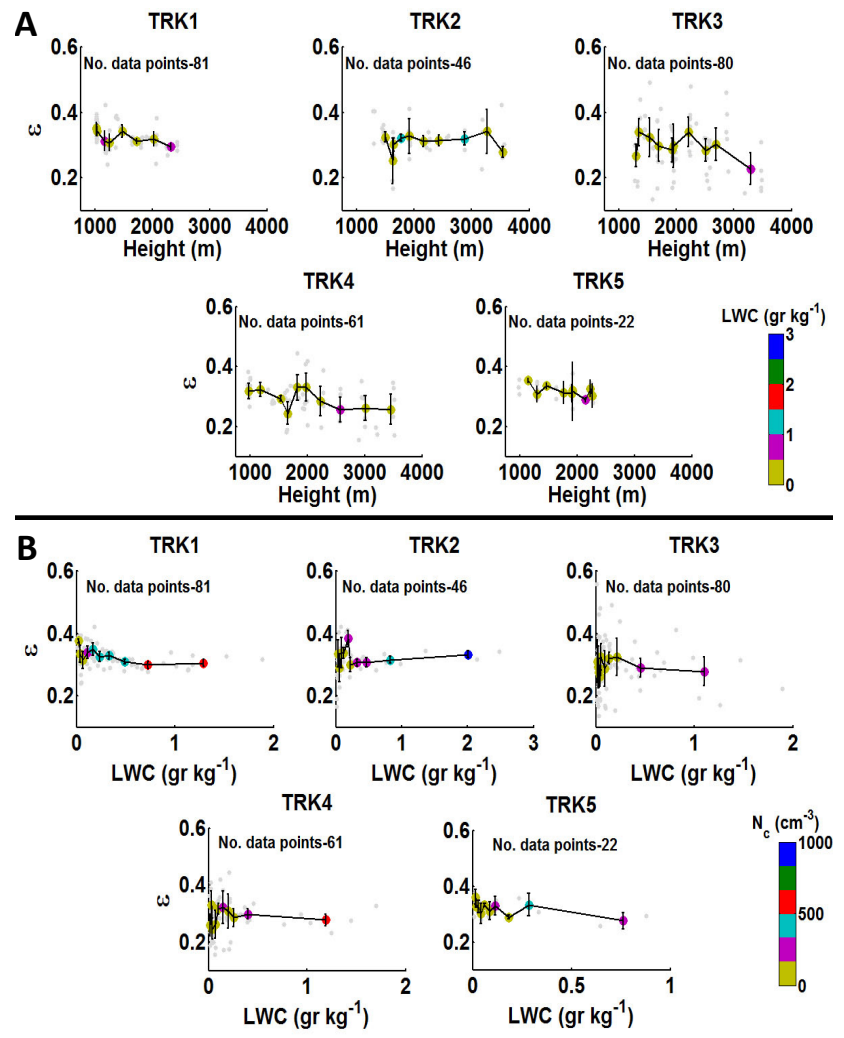

Figure 4. (a) Relative dispersion $(\varepsilon)$ vs. height above the ground with colors representing the liquid water content (LWC) and (b) $\varepsilon$ vs. LWC with colors representing the droplet concentration for the cloud boundary data points. Error bars represent the standard error of the average $\varepsilon$ for each height level (in a) and LWC (in b) with a confidence level of $95 \%$.

range, similar to the height binning that is shown in Fig. 2. This representation suggests that the relative dispersion is invariant to changes in average droplet radius (which by itself is highly correlated to the height within the cloud as explained in Fig. 2). This reinforces the conclusions drawn from Figs. 3 and 4.

Figure 6 combines all of the clouds' data together (except TRK3) and shows the $\varepsilon$ and its variance values as a function of LWC (Fig. 6a) and droplet concentration ( $N_{\mathrm{c}}$, Fig. 6b). The gray crosses represent $\varepsilon$ values, while the blue circles and red crosses represent the binned (number-based) mean of $\varepsilon$ and its standard deviation, respectively.

The results show that $\varepsilon$ values vary significantly $(\varepsilon \sim 0.1-$ 1.25 ) only in cloud segments with very low LWC and low drop concentrations (LWC $<\sim 0.01 \mathrm{~g} \mathrm{~kg}^{-1}$ and $N_{\mathrm{c}}<\sim$ $5 \mathrm{~cm}^{-3}$ ). For higher LWC and $N_{\mathrm{c}}$ values, the $\varepsilon$ fits within a relatively narrow range of values between 0.24 and 0.37 .

Figure 7 presents an additional analysis for the combined data set of all clouds together except TRK3. Figure 7a presents separate histograms of $\varepsilon$ for the measured cloud data obtained during each flight. This figure demonstrates that $\varepsilon$
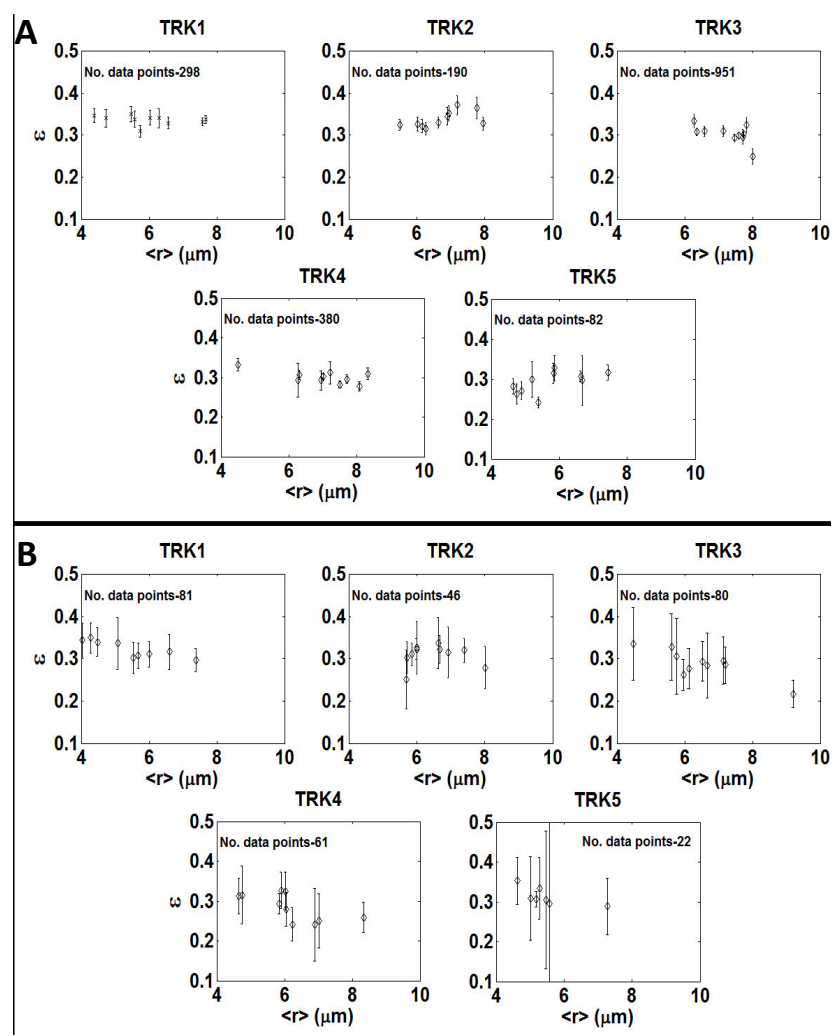

Figure 5. Relative dispersion vs. average radius for (a) the inner cloud data, and (b) the cloud boundaries. Error bars represent the standard error of the average $\varepsilon$ for each $\langle r\rangle$ level with a confidence level of $95 \%$.

variance decreases for flights associated with higher aerosol loading, which may be related to increasing $N_{\mathrm{c}}$ and/or LWC, and extension of the relative duration of the cloud mature stage with increasing aerosol loading as suggested by the second indirect effect (Albrecht et al., 1989). Figure 7b presents $\varepsilon$ histograms for different vertical parts of the clouds. This graph indicates that the variance of $\varepsilon$ tends to be smaller near the cloud base, compared to higher levels in the cloud. Possible reasons for this difference are discussed in the next section. This figure further suggests that $\varepsilon$ does not show any significant trend with increasing height above the cloud base.

\section{Discussion and summary}

Using in situ flight measurements of droplet size distributions in warm continental cumulus clouds, we investigated the dependence of $\varepsilon$ on cloud microphysical properties (LWC, $\langle r\rangle$ and $N_{\mathrm{c}}$ ).

The results suggest that the mean values of relative dispersion estimated for those cumulus clouds do not show any significant trend with LWC, height within the cloud, droplet concentration, aerosol loading or average droplet radius. On the other hand, a second-order effect on $\varepsilon$ distribution is 


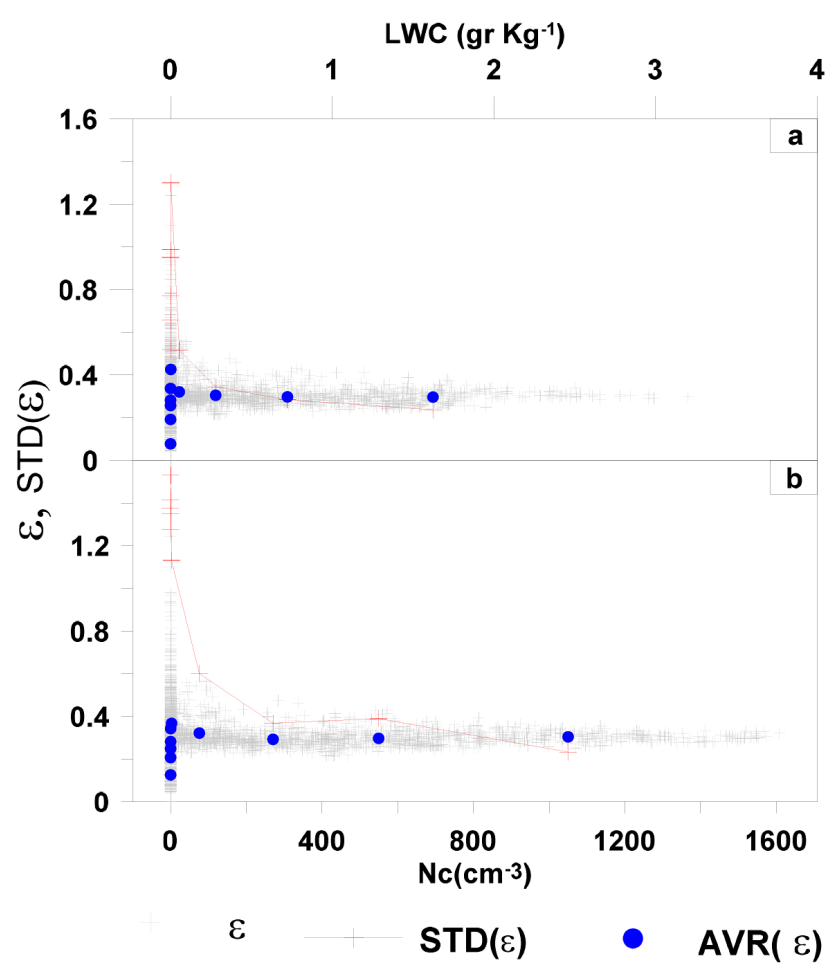

Figure 6. Relative dispersion and its variance as a function of cloud liquid water content (LWC) and droplet number $\left(N_{\mathrm{c}}\right)$. Relative dispersion $(\varepsilon)$, relative dispersion average (AVR $(\varepsilon)$ ) and relative dispersion variance (STD $(\varepsilon)$ ) are presented vs. LWC (a) and Nc (b). AVR $(\varepsilon)$ and STD $(\varepsilon)$ are presented as the average values of 10 number-based size bins.

clearly seen as a decrease in the variance of $\varepsilon$ with an increase in LWC and $N_{\mathrm{c}}$ (see Fig. 6).

Overall, the mean $\varepsilon$ values vary in the range of 0.24 to 0.37 . This is in agreement with previous studies which indicated that $\varepsilon$ tends to be bounded in a similar narrow range in warm cumuli (Pandithurai et al., 2012; Berg et al., 2011), stratus clouds (Peng et al., 2007) and stratocumulus clouds (Pawlowska et al., 2006).

Our findings also showed that the more scattered $\varepsilon$ values $(\sim 0.1-1.25)$ were associated with very low $L W C$ and $N_{\mathrm{c}}$, below threshold values of $\sim 0.01 \mathrm{~g} \mathrm{~kg}^{-1}$ and $\sim 5 \mathrm{~cm}^{-3}$, respectively (similar to the findings of Pandithurai et al., 2012; Zhao et al., 2006; and Deng et al., 2009). Measurement quality is low in those cloud regions, and this may be reflected as an increase in $\varepsilon$ variance. However, Tas et al. (2012) also showed, using detailed microphysical model, that $\varepsilon$ tends to be more scattered during the non-mature cloud development stages and for entrainment zones in the cloud, which are also associated with low LWC and $N_{\mathrm{c}}$ values.

Above the threshold levels of $N_{\mathrm{c}}$ and LWC, $\varepsilon$ showed fast convergence to average values. Deng et al. (2009) and Zhao et al. (2006) also indicated convergence of $\varepsilon$ to a narrow range (0.4-0.5) with increasing $N_{\mathrm{c}}$ associated with higher

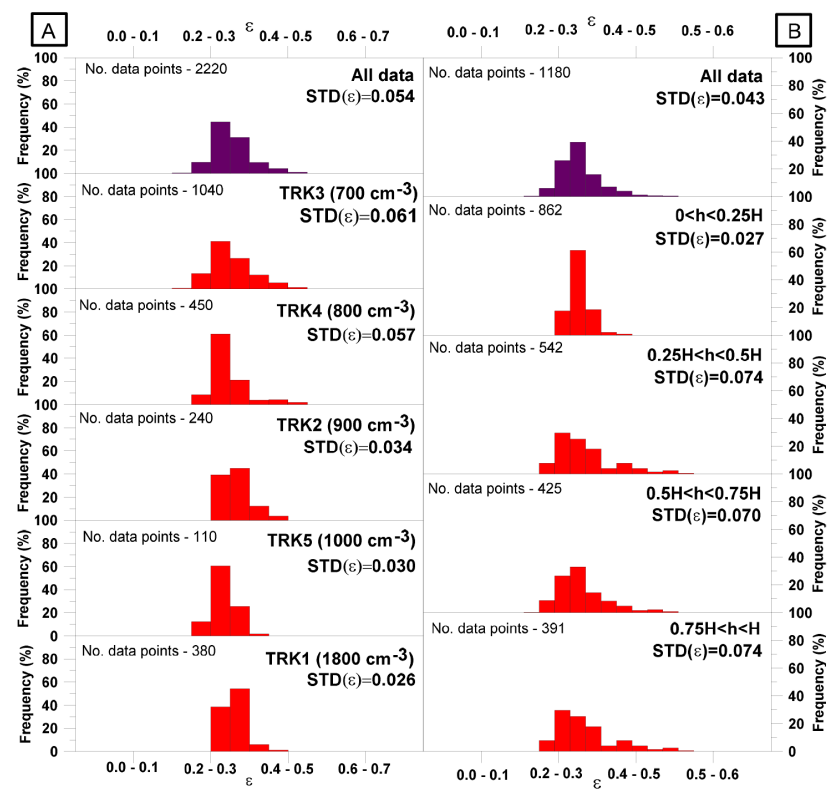

Figure 7. (a) Histograms of $\varepsilon$ for different aerosol loading values. The average aerosol loading for each flight (calculated at cloud base height) is presented. All histograms are based only on measured data associated with $N_{\mathrm{c}}>10 \mathrm{~cm}^{-3}$. (b) Histogram of $\varepsilon$ for different height ranges above the cloud base (indicated individually for each histogram by "h" range of the total cloud depth, "H"), excluding data collected during flight TRK3. All histograms are based only on measured data associated with $N_{\mathrm{c}}>10 \mathrm{~cm}^{-3}$. The top panel (All data) is based on data collected during all flights. Data collected during flight TRK3 were not used for any of the histograms.

pollution levels. Tas et al. (2012) showed that $\varepsilon$ fits into a narrow range for the core of a cumulus cloud in its mature stage, and for high LWC. In the present study, we also observed convergence of $\varepsilon$ with aerosol loading, which might be related to an increase in $N_{\mathrm{c}}$, LWC, or both. Note that an increase in aerosol loading can lead to extension of the mature stage, as a result of the second indirect effect (Albrecht et al., 1989). Therefore, the convergence of $\varepsilon$ due to either an increase in aerosol loading or an extension of the mature stage might be related to the same basic mechanism.

How reliable are the $\varepsilon$ estimations based on the CDP measurements? To estimate the $\varepsilon$ values correctly, one needs a full description of the droplet size distribution. Our measurements were limited to a range of radii between 1.5 and $25 \mu \mathrm{m}$. Clearly, $\varepsilon$ estimations deviate when the tail of the size distribution exceeds $25 \mu \mathrm{m}$ in radius, i.e., the estimated variance will be smaller than the real one (see TRK3 in Fig. 2) and as a consequence, the $\varepsilon$ values as well (see TRK 3 in Figs. 3 and 4).

The droplet size distributions for different vertical levels in each cloud are shown in Fig. 2, and it is evident that except for case TRK3, the concentration of droplets $>25 \mu \mathrm{m}$ is negligible. The relative dispersion values for the TRK3 case tended to decrease in the upper parts of the cloud, character- 
ized by larger LWC values. As indicated above, TRK3 was the cleanest case and it probably contained larger drops that were not measured by the probe. This suggests that in such cases, the estimation of $\varepsilon$ might be incorrect. Specifically, the contribution of the larger droplets is expected to be more significant for the case of larger LWC higher up in the cloud (see case TRK3 in Fig. 2). Therefore, the decrease in $\varepsilon$ for such data points might be an artifact due to incomplete representation of the large drops.

Our analysis suggests that a bias in $\varepsilon$ due to failure to detect the entire droplet size distribution, including the tail, of large drops, may serve as a criterion for the reliability of the measurement data for application in microphysical analyses. We are currently in the process of validating this hypothesis using data sets from other campaigns.

Regarding all of the other clouds and based on the relatively small $\langle r\rangle$ values (see Fig. 2), the sparse population of large droplets (for all clouds except TRK3), and the relatively high aerosol loading, we assume that drop growth in all of the measured clouds was dominated by the condensation process. It is well known that growth by condensation leads to an increase in $\langle r\rangle$ but a decrease in the width of the size distribution (smaller $\sigma$ ) (e.g., Rogers and Yau, 1989). However, the invariant nature of $\varepsilon$ values in this and some other studies suggests that additional processes occur simultaneously with condensation. These additional processes act to increase $\sigma$, such that the ratio of $\sigma$ to $\langle r\rangle$ remains relatively constant. Such processes may include drop growth by collision-coalescence or the formation of new droplets by activation of cloud condensation nuclei $(\mathrm{CCN})$ (increasing the number of the smaller droplets) or activation of giant $\mathrm{CCN}$ (which may increase the number of the larger drops). These scenarios act to broaden the droplet spectrum. In this study, we cannot determine which of these processes is more significant. Moreover, the contribution of each of the two processes to maintaining a relatively constant range of $\varepsilon$ may vary at different locations and stages of cloud evolution. Collectionbased processes are more important higher in the cloud and at later stages in the cloud's evolution, while activation of new particles is more important near the cloud base and in the early stages of its development.

Autoconversion and radiation parameterizations in many GCMs and CRMs are currently based on the estimated impact of aerosol loading on the magnitude of $\varepsilon$ (see Sect. 1). The present study uses airborne measurements to demonstrate that $\varepsilon$ is not correlated with LWC, $N_{\mathrm{c}}$ or $\langle r\rangle$, suggesting that $\varepsilon$ is relatively invariant to changes in the cloud's microphysical properties. On the other hand, variance in $\varepsilon$ was found to be correlated with LWC and $N_{\mathrm{c}}$, suggesting that $\varepsilon$ variance, rather than $\varepsilon$, does depend on the cloud's microphysical properties. This finding may pave the way for improving autoconversion and radiation parameterizations, which rely on $\varepsilon$ values in CRMs and GCMs. However, further testing of the correlation of $\varepsilon$ with these parameters under different ambient conditions and adiabatic and nonadiabatic cloud conditions is warranted.

Acknowledgements. This work was supported by the Israel Science Foundation (grant 1172/10). CARI was funded by the Istanbul Metropolitan Municipality (IMM) through Seeding Operations and Atmospheric Research (SOAR).

Edited by: M. C. Facchini

\section{References}

Ackerman, A. S., Toon, O. B., Taylor, J. P., Johnson, D. W., Hobbs, P. V., and Ferek, R. J.: Effects of aerosols on cloud albedo: evaluation of Twomey's parameterization of clouds susceptibility using measurements of ship tracks, J. Atmos. Sci., 57, 2684-2695, 2000.

Altaratz, O., Koren, I., Remer, L. A., and Hirsch, E.: Review: cloud invigoration by aerosols - coupling between microphysics and dynamics, Atmos. Res., 140, 38-60, 2014.

Albrecht, B.: Aerosols, cloud microphysics, and fractional cloudiness, Science, 245, 1227-1230, 1989.

Andreae, M. O., Rosenfeld, D., Artaxo, P., Costa, A. A., Frank, G. P., Longo, K. M., and Silva-Dias, M. A. F.: Smoking rain clouds over the Amazon, Science, 303, 1337-1342, doi:10.1126/science.1092779, 2004.

Axisa, D., Rosenfeld, J., Santarpia, W., Woodley, and Collins, D.: The Southern Plains Experiment in Cloud Seeding of Thunderstorms for Rainfall Augmentation (SPECTRA) project: operational tools used towards verifying glaciogenic and hygroscopic seeding conceptual models, case studies and preliminary results, Preprints, 16th Conf. on Planned and Inadvertent Weather Modification, 9-13 January 2001, San Diego, CA, Amer. Meteor. Soc., Paper 6.6, 2005.

Berg, L. K., Berkowitz, C. M., Barnard, J. C., Senum, G., and Springston, S. R.: Observations of the first aerosol indirect effect in shallow cumuli, Geophys. Res. Lett., 38, L03809, doi:10.1029/2010GL046047, 2011.

Daum, P. and Liu, Y.: Dispersion of cloud droplet size distributions, cloud parameterizations, and indirect aerosol effects, paper presented at 13th ARM Science Team Meeting, Atmos. Radiat. Meas. Clim. Res. Facility, US Dep. of Energy, Daytona Beach, Fla., 14-18 March 2003.

Deng, Z., Zhao, C., Zhang, Q., Haung, M., and Ma, X.: Statistical analysis of properties and parameterization of effective radius of warm cloud in Beijing area, Atmos. Res., 93, 888-896, 2009.

Feingold, G., Eberhard, W. L., Veron, D. E., and Previdi, M.: First measurements of the Twomey indirect effect using ground-based remote sensors, Geophys. Res. Lett., 30, 1287, doi:10.1029/2002GL016633, 2003.

Hansen, J. E. and Travis, L. D.: Light-scattering in planetary atmospheres, Space Sci. Rev., 16, 527-610, doi:10.1007/BF00168069, 1974. Hsieh, W. C., Nenes, A., Flagan, R. C., Seinfeld, J. H., Buzorius, G., and Jonsson, H.: Parameterization of cloud droplet size distributions: Comparison with parcel models and observations, J. Geophys. Res., 114, D11205, doi:10.1029/2008JD011387, 2009. 
Hsieh, W. C., Nenes, A., Flagan, R. C., Seinfeld, J. H., Buzorius, G., and Jonsson, H.: Parameterization of cloud droplet size distributions: comparison with parcel models and observations, J. Geophys. Res., 114, D11205, doi:10.1029/2008JD011387, 2009.

Koren, I., Kaufman, Y. J., Rosenfeld, D., Remer, L. A., and Rudich, Y.: Aerosol invigoration and restructuring of Atlantic convective clouds, Geophys. Res. Lett., 32, L14828, doi:10.1029/2005GL023187, 2005.

Liu, Y. and Daum, P. H.: Spectral dispersion of cloud droplet size distributions and the parameterization of cloud droplet effective radius, Geophys. Res. Lett., 27, 1903-1906, doi:10.1029/1999GL011011, 2000a.

Liu, Y. and Daum, P. H.: Which size distribution function to use in parameterization of effective radius, paper presented at 13th International Conference on Clouds and Precipitation, 14-18 August 2000, Int. Comm. on Clouds and Precip. Reno, Nev., $2000 \mathrm{~b}$.

Liu, Y. and Daum, P. H.: Anthropogenic aerosols: indirect warming effect from dispersion forcing, Nature, 419, 580-581, doi:10.1038/419580a, 2002.

Liu, Y., Daum, P. H., and McGraw, R.: Size truncation effect, threshold behavior, and a new type of autoconversion parameterization, Geophys. Res. Lett., 32, L11811, doi:10.1029/2005GL022636, 2005.

Liu, Y., Daum, P. H., McGraw, R., and Miller, M.: Generalized threshold function accounting for effect of relative dispersion on threshold behavior of autoconversion process, Geophys. Res. Lett., 33, L11804, doi:10.1029/2005GL0255000, 2006a.

Liu, Y., Daum, P. H., and Yum, S. S.: Analytical expression for the relative dispersion of the cloud droplet size distribution, Geophys. Res. Lett., 33, L02810, doi:10.1029/2005GL024052, 2006b.

Liu, Y., Daum, P. H., Guo, H., and Peng, Y.: Dispersion bias, dispersion effect and aerosol-cloud conundrum, Environ. Res. Lett., 3, 045021, doi:10.1088/1748-9326/3/4/045021, 2008.

Lu, M.-L. and Seinfeld, J. H.: Effect of aerosol number concentration on cloud droplet dispersion: a large-eddy simulation study and implications for aerosol indirect forcing, J. Geophys. Res., 111, D02207, doi:10.1029/2005JD006419, 2006.

Lu, M.-L., Feingold, G., Jonsson, H. H., Chuang, P. Y., Gates, H., Flagan, R. C., and Seinfeld, J. H.: Aerosol-cloud relationships in continental shallow clouds, J. Geophys. Res., 113, D15201, doi:10.1029/2007JD009354, 2008.

Ma, J., Chen, A., Wang, W., Yan, P., Liu, H., Yang, S., Hu, Z., and Lelieveld, J.: Strong air pollution causes widespread haze-clouds over China, J. Geophys. Res., 115, D18204, doi:10.1029/2009JD013065, 2010.

Martin, G. M., Johnson, D. W., and Spice, A.: The measurement and parameterization of effective radius of droplets in warm stratocumulus clouds, J. Atmos. Sci., 51, 1823-1842, doi:10.1175/15200469(1994)051<1823:TMAPOE>2.0.CO;2, 1994.

Martins, J. A. and Silva Dias, M. A. F.: The impact of smoke from forest fires on the spectral dispersion of cloud droplet size distributions in the Amazonian region, Environ. Res. Lett., 4, 015002 , doi:10.1088/1748-9326/4/1/015002, 2009.

McFarquhar, G. M. and Heymsfield, A. J.: Parameterization of INDOEX microphysical measurements and calculations of cloud susceptibility: applications for climate studies, J. Geophys. Res., 106, 28675-28698, doi:10.1029/2000JD900777, 2001.
Miles, N. L., Verlinde, J., and Clothiaux, E. E.: Cloud droplet size distributions in low-level stratiform clouds, J. Atmos. Sci., 57, 295-311, 2000.

Pandithurai, G., Dipu, S., Prabha, T. V., Maheskumar, R. S., Kulkarni, J. R., and Goswami, B. N.: Aerosol effect on droplet spectral dispersion in warm continental cumuli, J. Geophys. Res., 117, D16202, doi:10.1029/2011JD016532, 2012.

Pawlowska, H., Grabowski, W. W., and Brenguir, J.-L.: Observations of the width of cloud droplet spectra in stratocumulus, Geophys. Res. Lett., 33, L29810, doi:10.1029/2006GL026841, 2006.

Peng, Y. and Lohmann, U.: Sensitivity study of the spectral dispersion of the cloud droplet size distribution on the indirect aerosol effect, Geophys. Res. Lett., 30, 1507, doi:10.1029/2003GL017192, 2003.

Peng, Y., Lohmann, U., Leaitch, R., and Kulmala, M.: An investigation into the aerosol dispersion effect through the activation process in marine stratus clouds, J. Geophys. Res., 112, D11117, doi:10.1029/2006JD007401, 2007.

Rogers, R. R. and Yau, M. K.: A Short Course in Cloud Physics, 3rd edn., Pergamon Press, Oxford, 1989.

Rosenfeld, D. and Feingold, G.: Explanation of the discrepancies among satellite observations of the aerosol indirect effects, Geophys. Res. Lett., 30, 1776, doi:10.1029/2003GL017684, 2003.

Rotstayn, L. D. and Liu, Y.: Sensitivity of the first indirect aerosol effect to an increase of cloud droplet spectral dispersion with droplet number concentration, J. Climate, 16, 3476-3481, doi:10.1175/1520-0442, 2003.

Slingo, A.: A GCM parameterization for the shortwave Radiative properties of water clouds, J. Atmos. Sci., 46, 1419-1427, doi:10.1175/1520-0469, 1989.

Small J. D., Chuang, P. Y., and H. H. Jonsson, Microphysical imprint of entrainment in warm cumulus, Tellus B, 65, 19922, doi:10.3402/tellusb.v65i0.19922, 2013.

Tao, W.-K., Chen, J.-P., Li, Z., Wang, C., and Zhang, C.: Impact of aerosols on convective clouds and precipitation, Rev. Geophys., 50, RG2001, doi:10.1029/2011RG000369, 2012.

Tas, E., Koren, I., and Altaratz, O.: On the sensitivity of droplet size relative dispersion to warm cumulus cloud evolution, Geophys. Res. Lett., 39, L13807, doi:10.1029/2012GL052157, 2012.

Teller, A., Axisa, D., Bruintjes, R., Collins, D., Mutlu, A., Kluzek, C., Pocernich, M., Buseck, P. R., Freney, E., Tessendorf, S., Hunter, S., Şen, O., Kocak, K., Toros, H., Köse, A., and Tunc, M.: Cloud and Aerosol Research in Istanbul Final Report 2007-2008, NCAR/RAL, Boulder, CO, 2008.

Twomey, S.: The influence of pollution on the short wave albedo of clouds, J. Atmos. Sci., 34, 1149-1152, 1977.

Xie, X., Liu, X., Peng, Y., Wan, Y., Yue, Z., and Li., X.: Numerical simulation of clouds and precipitation depending on different relationships between aerosol and cloud droplet spectral dispersion, Tellus B, 65, 1-17, 2013.

Yum, S. S. and Hudson, J. G.: Adiabatic predictions and observations of cloud droplet spectral broadness, Atmos. Res., 73, 203 223, doi:10.1016/j.atmosres.2004.10.006, 2005.

Zhao, C., Tie, X., Brasseur, G., Noone, K. J., Nakajima, T., Noone, K. J., Nakajima, T., Zhang, Q., Zhang, R., Huang, M., Duan, Y., Li, G., and Ishizaka, Y.: Aircraft measurements of cloud droplet spectral dispersion and implications for indirect aerosol radiative forcing, Geophys. Res. Lett., 33, L16809, doi:10.1029/2006GL026653, 2006. 